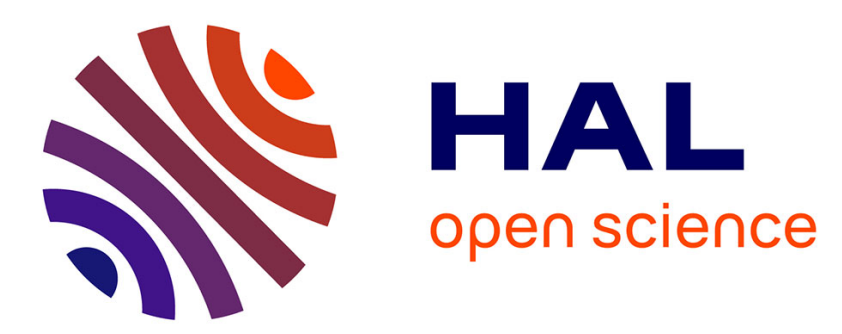

\title{
Studying and modeling of submerged aquatic vegetation environments seen by a single beam echosounder
}

\author{
Coralie Monpert, Michel Legris, Claire Noel, Benoit Zerr, Jean-Marc Le
}

Caillec

\section{- To cite this version:}

Coralie Monpert, Michel Legris, Claire Noel, Benoit Zerr, Jean-Marc Le Caillec. Studying and modeling of submerged aquatic vegetation environments seen by a single beam echosounder. Proceedings of meetings on acoustics, 2012, 17, pp.070044 - 070044. hal-00942712

\section{HAL Id: hal-00942712 \\ https://hal.science/hal-00942712}

Submitted on 10 Feb 2014

HAL is a multi-disciplinary open access archive for the deposit and dissemination of scientific research documents, whether they are published or not. The documents may come from teaching and research institutions in France or abroad, or from public or private research centers.
L'archive ouverte pluridisciplinaire HAL, est destinée au dépôt et à la diffusion de documents scientifiques de niveau recherche, publiés ou non, émanant des établissements d'enseignement et de recherche français ou étrangers, des laboratoires publics ou privés. 


\title{
Proceedings of Meetings on Acoustics
}

Volume 17, 2012

http://acousticalsociety.org/

\author{
ECUA 2012 11th European Conference on Underwater Acoustics \\ Edinburgh, Scotland \\ 2 - 6 July 2012 \\ Session UW: Underwater Acoustics
}

\section{UW42. Studying and modeling of submerged aquatic vegetation environments seen by a single beam echosounder}

\author{
Coralie Monpert $^{1}$, Michel Legris ${ }^{1}$, Claire Noel ${ }^{2}$, Benoit Zerr ${ }^{1}$ and Jean Marc Le Caillec ${ }^{3}$ \\ ${ }^{1}$ ENSTA Bretagne, BREST, FRANCE \\ ${ }^{2}$ Semantic TS, Sanary sur mer, France \\ ${ }^{3}$ Telecom Bretagne, Brest, France
}

For both environmental and economic reasons, it is important to map the distribution of submerged aquatic vegetation. Acoustic technologies seem to be the more efficient and cost effective methods for that. Many papers have been published on underwater vegetation detection using an acoustic echo-sounder. However, few general studies have been performed to quantitatively understand the acoustic process of scattering from underwater vegetation.

First, the effect of fields of vegetation on the temporal signal of the echo-sounder is studied. Real echo-sounder data obtained from different sites and different kinds of submerged aquatic vegetation was used. In most cases, the vegetation signal has a relatively strong backscatter signal before the bottom detection time and a less abrupt leading edge. However, different species-dependant behaviors were found.

In order to explain this phenomenon and to characterize underwater vegetation, a model, based on the sonar equation, is developed to highlight the interaction between the acoustic wave and the environment composed of underwater vegetation. The result is a submerged aquatic vegetation apparent scattering index which can be used to help to characterize underwater vegetation.

Corresponding author: Coralie Monpert at coralie.monpert@ensta-bretagne.fr.

Published by the Acoustical Society of America through the American Institute of Physics

C2012 Acoustical Society of America [DOI: 10.1121/1.4772739]

Received 19 Nov 2012; published 5 Dec 2012

Proceedings of Meetings on Acoustics, Vol. 17, 070044 (2012) 


\section{INTRODUCTION}

Coastal shallow water studies are mainly motivated by ecological and economic issues. One important item is the study of Submerged Aquatic Vegetation (SAV). Ecologically, SAV beds stabilize bottom sediments through their roots, attenuate currents and waves, promote sedimentation and reduce erosion [1].They also provide shelter and refuge for adult animals and serve as nurseries for juvenile fish [2]. The infauna and epifauna of SAV also serve as prey for larger invertebrates and fish [3]. Furthermore, the distribution of vegetation meadows is an indicator of the water quality [4]. Economically, seaweeds (algae) are used in industry very extensively [5]. So, in order to protect and detect general ecosystem changes, an accurate monitoring of SAV beds is required.

Numerous techniques for characterizing and monitoring SAV have been used. These can be roughly divided in three categories: physical (manual) methods, optical methods, and acoustic methods. Physical techniques include direct physical sampling and observation by divers [6]. Although they provide the greatest level of fidelity, they are both time consuming and labor intensive. Optical methods use imagery acquired from airbone, spaceborne sensors or underwater cameras [7]. These techniques work well under ideal conditions, but their performance is severely degraded by uncontrollable factors such as poor water clarity, water surface roughness and clouds. Nowadays, the most efficient techniques for mapping and monitoring the subsurface ocean over large areas are acoustic methods [8]. There are three general kinds of acoustic systems: side-scan sonars, multibeam and single beam echo-sounders. According to previous studies, it is easier to separate SAV and bottom reflectivity with the help of temporal information in the water column. Most of the time, single beam echo-sounders give that information contrary to side-scan sonars and conventional bathymetric multibeam echo-sounders. Moreover, single beam echo-sounders are not affected by the dependence on the grazing angle. Therefore, the single beam echo-sounder seems to be the most appropriate tool to gather information about SAV.

Many studies have been carried out to characterize and monitor SAV with the echo time series of a single beam echo-sounder $[9,10]$. Without ground truth data and calibration, very little information about SAV is available. The absence/presence of vegetation and the height of the canopy are obtained without difficulty, but it seems more difficult to determine the types of species and densities. Obtaining these SAV properties, using only a single beam echo-sounder, is tested in our work, by comparing real data of three species of SAV and their substrate with a physical model. After a presentation of the raw data and their pre-processing, the results are shown. Then, the model, designed to extract new information about vegetation environments, is presented and results are discussed. 


\section{DATASET}

\subsection{Description of SAV available from our data}

In this paper, the SAV comparison is limited to three species, Laminaria hyperborea, Posidonia oceanica and Zostera marina.

\subsubsection{Laminaria hyperborea}

Laminaria hyperborea is a species of large brown alga; it is kelp of the family Laminariaceae which is found in the sublittoral zone of the northern Atlantic Ocean. Usually, Laminaria hyperborea attaches itself to rock or other hard substrata. Its holsfast is large and conical. The stipe is stiff, rough textured, thick at the base and tapers towards the frond. It measures about 1-2m long and it stands erect when out of water. The blade is large, tough, flat and divided into 5-20 straps of 5-10cm width [5].

\subsubsection{Posidonia oceanica}

Posidonia oceanica is a seagrass species that is endemic to the Mediterranean Sea. It is a flowering plant which lives in dense meadows which are found at depths from 1-35m on sand. The rhizome type stems have two possible forms: one growing beneath the sand and other rising above the sand. This arrangement of rhizomes eventually forms a mat. The surface contains the active parts of the plant (the leaves), whereas the centre is a dense network of roots. The leaves are ribbon-like, appearing in tufts of 6 or 7 , and up to $1.5 \mathrm{~m}$ long. Average leaf width is around $1 \mathrm{~cm}$. The leaf terminus is rounded or sometimes absent because of damage [11].

\subsubsection{Zostera marina}

Zostera marina is a species of seagrass that is found mostly in the northern sections of north Atlantic and Pacific coasts. It is a flowering plant which lives at depths from $0-10 \mathrm{~m}$. It anchors via rhizomes in sandy or muddy substrates. Rhizomes are $2-6 \mathrm{~mm}$ width with $5-20$ roots at each node. They are creeping and blind the sediment. The leaves are hairlike and narrow and measure up to $1.2 \mathrm{~cm}$ wide and may reach over a $1 \mathrm{~m}$ long. Leaf sheaths form a tube around stem [11].

\subsection{Data acquisition}

The data used for this study were acquired by the Semantic TS Company using a small hydrographic vessel [12]. During all the surveys, the same acoustic system with fixed settings was used. It consists in a Simrad ES60 echo-sounder by Kongsberg Company. This echo-sounder allows one to obtain echo time series at 38 and $200 \mathrm{kHz}$, for each ping. For low and high frequencies, the beamwidths are $15^{\circ}$ and $7^{\circ}$ and the pulses lengths are 256 and $64 \mu \mathrm{s}$, respectively. The data for this project are acquired in .raw format, which are read into Matlab where the processing is performed.

Each survey contains only one type of SAV and ground truth vegetation species was obtained by divers. On June $9^{\text {th }}, 2010$, a survey was carried out in Lézardrieux, in the north of France. In that area, Laminaria hyperborea was found. On June $17^{\text {th }}, 2010$, bare sand and sand with Zostera marina were surveyed in the site of Douarnenez in the north of France. Finally, on September $22^{\text {nd }}, 2009$, a survey was carried out in La Vaille (south of France) where bare sand and sand with Posidonia oceanica were observed. 


\section{PRE-PROCESSING}

\subsection{General principle}

In this work, the pre-processing step is essential to obtain the average backscattering intensity as well as to do a solid comparison between the different type of SAV and their substrate. To estimate the average backscattering intensity, the ping to ping variability has to be reduced. At high frequency, it is mainly due to speckle. To filter it, stacking of several echoes is done with a sliding window of 10 pings. In order to carry out a solid comparison, the average backscattering intensity should only depend on bottom reflectivity. However, echo time series are affected by other parameters, mainly depth and seabed slope [13]. Therefore, pre-processing is essential to reduce the dependence on depth and slope. To be independent of slope, only data on relatively flat seabed are studied. To weaken depth effect, depth-compensation is performed.

\subsection{Depth compensation}

Depth has an important influence on the shape of the echo time series. In fact, echoes from deep seafloors are expanded in time relative those from shallow seafloors. Moreover, the total loss of intensity due to spreading, footprint and attenuation increases as depth increases. Therefore, depth compensation is divided in three steps: bottom detection; time-scaling; and power correction. Time scaling and power correction are done according to the methods described in [14].

Bottom detection is a common challenge. Indeed, if the bottom is rough, three pieces of information may be obtained: the minimum, maximum and mean seabed depth. In our case, the mean bottom is desired. It was observed that, in the echo time series, the localisation of the mean bottom appears at approximately a half pulse length in time before the maximum of the echo. In fact, if the roughness is considered as Gaussian distributed and the skewness of the signal is light [15], then the maximum reflectivity occurs when the pulse length is centred on the mean bottom. Because of the high ping to ping variability of the data, it is difficult to detect the true maximum of the echo. Therefore, data is filtered with a mean filter with a width the pulse length.

The pre-processing step is mainly a depth-compensation algorithm. With this step, it is possible to perform some quantitative studies. However, it is necessary to be aware that time-scaling and power corrections are not sufficient to make the echoes acquired at various depths similar. The slight difference of shape in the echoes is due to macro-roughness which does not increase linearly with depth and which is not compensated here [15]. With the help of a statistical model developed by [16], a rapid study of the depth-compensation sensibility was done. It was observed that for a compensation of $3 \mathrm{~m}$, an error in power of $1 \mathrm{~dB}$ and a maximum shift of $10 \mathrm{~cm}$ in the mean bottom depth are introduced.

\section{DATA ANALYSES}

\subsection{Results}

In order to understand the interaction between the acoustic wave and SAV, the first step is to observed differences between a bare substrate and a substrate with SAV, at 38 and $200 \mathrm{kHz}$. Unfortunately, this information was only available for two species: Posidonia oceanica and Zostera marina.

Figure 1 shows the echograms of the average backscattering intensity for these two species at 38 and $200 \mathrm{kHz}$. The mean detected bottom is shown with a blue line. The data are pre-processed according to the section 3, where it was shown that, in agreement with the previous studies, an absence/presence localisation can be done and the height of the canopy can be determined. Secondly, it is possible to 
note a perfect continuity between the mean bottom of the bare substrate and the substrate with SAV, at both frequencies. Moreover, there is no specific echo at the interface between the water and the SAV environment. Thus, there is not a large impedance break between the two environments.

In Figure 2, Posidonia oceanica and Zostera marina are compared with their respective bare substrate. Data are pre-processed according to the section 3. Depth compensation at $13 \mathrm{~m}$ is done for the Posidonia oceanica environment and at $7.5 \mathrm{~m}$ for the Zostera marina environment. For the two species, a significant difference is observed between the bare substrate and its SAV. In both cases, the signal from the vegetation has a relatively strong backscatter component before the bottom detection time. For Posidonia oceanica, this feature is more salient at $200 \mathrm{kHz}$. For Zostera marina, it is nearly the same at both frequencies. Seabed responses give other information: the sand reflectivity is attenuated when it is covered with SAV. However, the behavior is different and depends on the species. The absorption is significant for Posidonia oceanica $(-18 \mathrm{~dB}$ at $38 \mathrm{kHz},-10 \mathrm{~dB}$ at $200 \mathrm{kHz})$, and smaller for Zostera marina $(-3 \mathrm{~dB}$ at $38 \mathrm{kHz},-5 \mathrm{~dB}$ at $200 \mathrm{kHz})$.

Figure 3 presents the average backscattering intensity of the three species of SAV introduced in section 2, at 38 and $200 \mathrm{kHz}$. Data are pre-processed according to the section 3. A depth-compensation is done at the mean depth of all the data (i.e. $10 \mathrm{~m})$. The first conclusion is that at both frequencies, before the bottom detection time and up to the canopy top, the shape is characteristic of the species. Indeed, in that part of the signal, Posidonia oceanica has a constant increase of reflectivity until the bottom detection time. For Zostera marina, the signal starts with a little step of reflectivity and then a constant increase until the bottom detection time. For Laminaria hyperborea, the step is higher than for the other species and the reflectivity level stays constant until the bottom detection time. Results also show that, at $38 \mathrm{kHz}$, Laminaria hyperborea and Zostera marina have the same maximum level of reflectivity which is higher than the one of Posidonia oceanica. At $200 \mathrm{kHz}$, the situation is different; Laminaria hyperborea and Posidonia oceanica have the same maximum level which is lower than the maximum of reflectivity of Zostera marina.

\subsection{Data analysis}

First, it is important to note that one ping does not translate only the response of the vegetation, but of the entire environment into the footprint of the single beam echo-sounder. Thus the acoustic signal is the response of the environment consisting of SAV and water.

Figure 1 has not highlighted a difference of impedance between the bare substrate and the SAV. Thus, the sound velocity and the density of the SAV environment can be approximated by the water sound velocity and density. Moreover, a surface reflection at the water/SAV interface cannot be considered. However, Figure 2 shows a relatively strong backscatter before the bottom. Therefore, the SAV environment has its own backscattering coefficient which can be modelled as volume reverberation. This volume backscattering coefficient into SAV has different shape, dependent on species, so it should help species characterization (Figure 3). Signal attenuation in presence of SAV seems to be specific to species too. In fact, Posidonia oceanica has a higher absorption than Zostera marina (Figure 2).

According to those findings, additional information other than the height of canopy and the presence of SAV may be extracted with a single beam echo-sounder: volume backscattering and absorption coefficient of the SAV environment can also be observed. However, direct measurements of these two coefficients are difficult to obtain. In the next part, with the help of a numerical model, the quantification of this information is studied. 

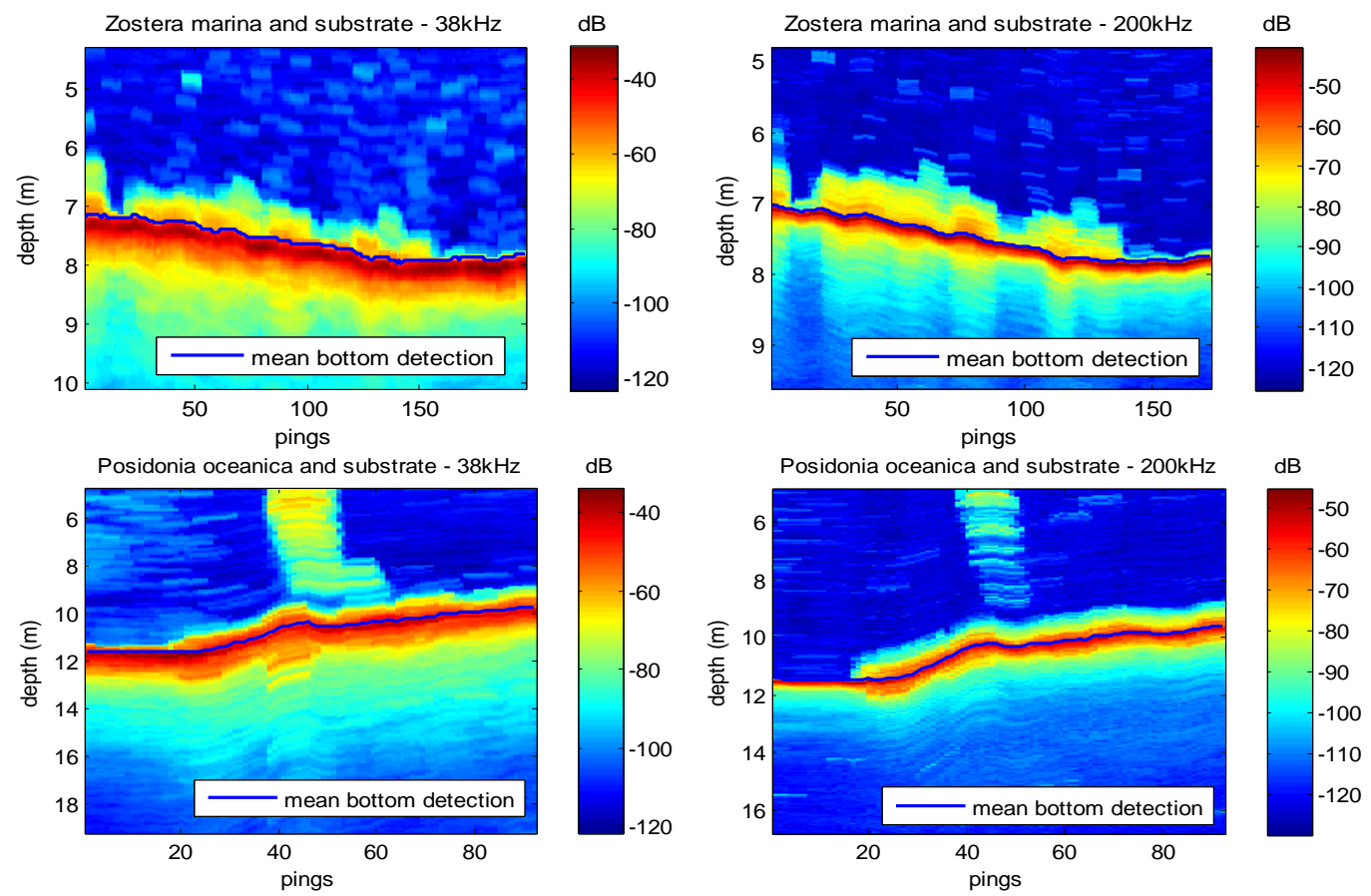

Figure1: Echogram of the average backscattering intensity in $\mathrm{dB}$ (received power reference of $1 \mathrm{~W}$. At the emission, the power is $100 \mathrm{~W}$ at $38 \mathrm{kHz}$ and $300 \mathrm{~W}$ at $200 \mathrm{kHz}$ ). Localisation of the mean bottom in meter (blue line).

\section{THE SAV APPARENT SCATTERING INDEX}

\subsection{Model}

According to the previous observations and information provided by the manufacturer (Kongsberg Maritime), it is possible to link the received power with the volume backscattering and the absorption coefficient [17]. The first hypothesis is that the sound velocity and the density of the SAV environment are assumed to be the same as water. Secondly, no surface reflection at the interface water/SAV is observed. Finally, as we work in shallow water $(0-15 \mathrm{~m})$, the acoustic wave curvature can be considered negligible. Therefore, the SAV environment can be viewed as homogeneous into the insonified volume at the instant $t$.

Thus, to be in agreement with the real data into the SAV environment, the average backscattering intensity, in $\mathrm{dB}$ and inside the vegetation, is modelled at each corresponding time using the sonar equation:

$$
P_{F}(t)=10 \log \left(\frac{P_{\Theta} G_{0}^{2} \lambda^{2} c \tau \psi}{32 \pi^{2}}\right)-2 \alpha r_{c}-20 \log (r(t))+S_{v}(r(t))-2 \beta(r(t))\left(r(t)-r_{0}\right)
$$

where $P_{\gamma}$ is the received power at the time $\mathrm{t}(\mathrm{dB}$ re $1 \mathrm{~W}), P_{\theta}$ is the transmitted power $(\mathrm{W}), G_{0}$ is the transducer peak gain (non-dimensional), $\lambda$ is the wavelength $(\mathrm{m}), c$ is the sound velocity $(\mathrm{m} / \mathrm{s}), \pi$ is the transmit pulse duration (s), $\psi$ is the equivalent solid angle (rad), $\alpha$ is the absorption coefficient of water $(\mathrm{dB} / \mathrm{m}), r_{c}$ is the distance between the transducer and the top of the canopy $(\mathrm{m}), r$ is the distance 
between the transducer and the wave at time t, $S_{V}$ and $\beta$ are the volume backscattering coefficient (dB re $1 \mathrm{~m}^{-1}$ ) and the accumulated absorption coefficient starting from the canopy top $(\mathrm{dB} / \mathrm{m})$ of the SAV environment at time t.

The goal is to find $S_{w}$ and $\beta$ for each time in the SAV environment. However, to be in agreement with the real data, it is not suitable to consider $S_{V}$ and $\beta$ as constants, since the increase of $P_{F}$ from the vegetation layer is gradual. Therefore, probably, $S_{w}$ and $\beta$ vary during the propagation. Unfortunately, we do not have enough equations to immediately solve the problem.

However, in order to define new descriptor about the SAV environment, the SAV apparent scattering index $A_{V}$ is introduced, defined as:

$$
\begin{aligned}
A_{v} & =S_{v}(r(t))-2 \beta(r(t))\left(r(t)-r_{c}\right) \\
& =P_{r}(t)-10 \log \left(\frac{P_{\theta} G_{0}^{2} \pi^{2} c \tau \psi}{32 \pi^{2}}\right)+2 \alpha r_{c}+20 \log (r(t))
\end{aligned}
$$
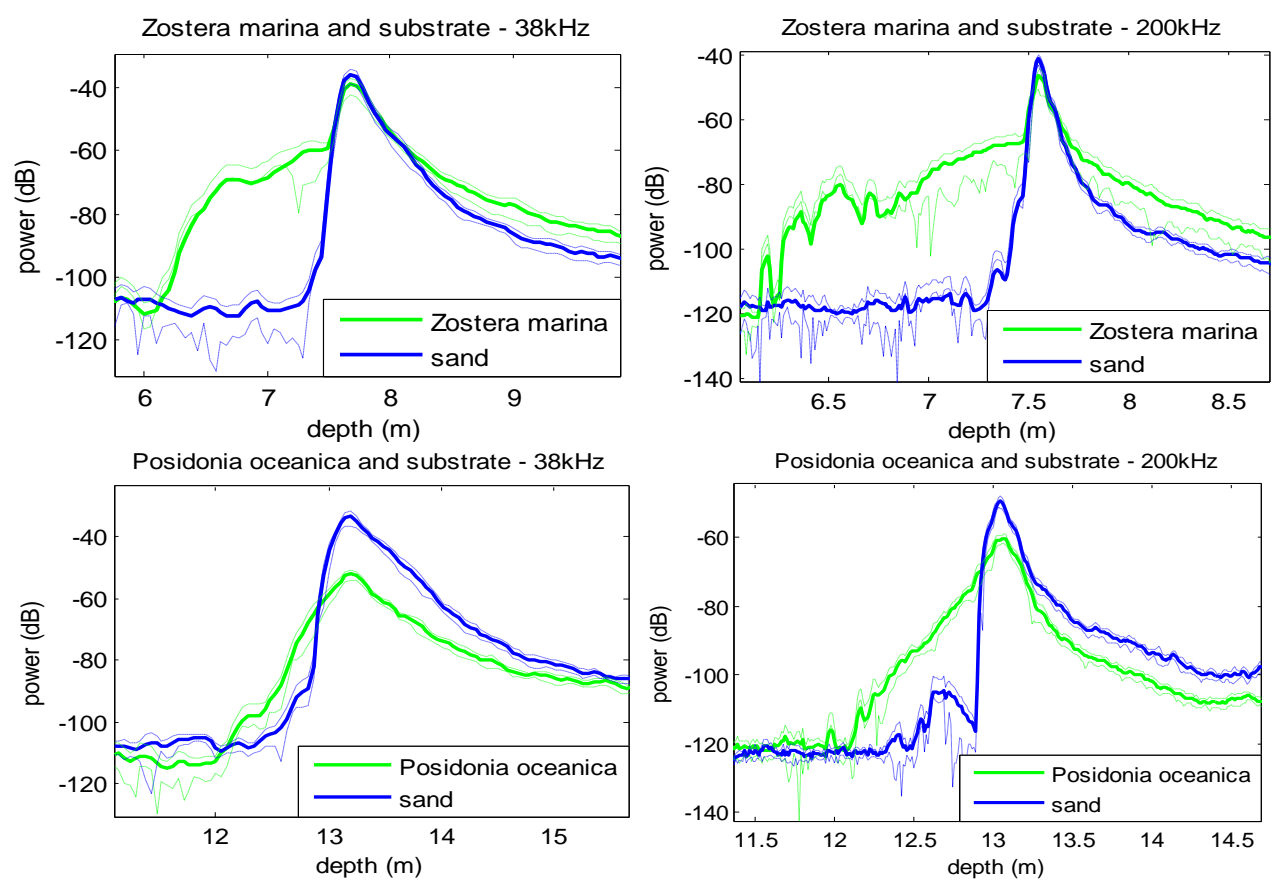

Figure 2: The average backscattering intensity for different types of seabed and frequencies, in solid lines (received power for a reference of $1 \mathrm{~W}$. At the emission, the power is $100 \mathrm{~W}$ at $38 \mathrm{kHz}$ and $300 \mathrm{~W}$ at $200 \mathrm{kHz}$ ). The dashed lines represent the empirical standard deviation. 

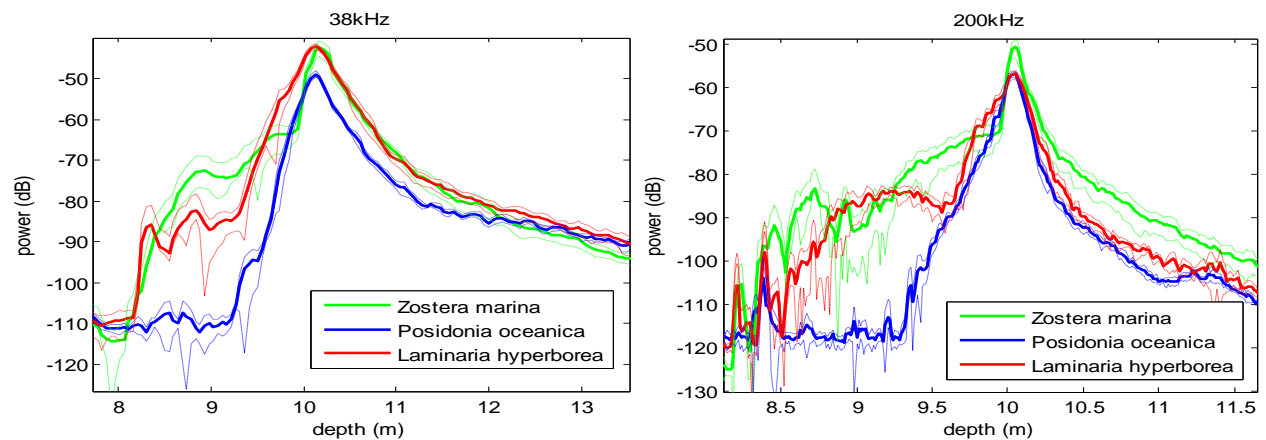

Figure 3: The average backscattering intensity for different types of SAV and frequencies, in solid lines (received power for a reference of $1 \mathrm{~W}$. At the emission, the power is $100 \mathrm{~W}$ at $38 \mathrm{kHz}$ and $300 \mathrm{~W}$ at 200 $\mathrm{kHz}$ ). The dashed lines represent the empirical standard deviation.

\subsection{Results}

Figure 4 shows the SAV apparent scattering index, $A_{W}$, at 38 and $200 \mathrm{kHz}$, for the species available. $A_{V}$ combines the volume backscattering and the wave extinction. The three species have different behaviours. For all the species, the SAV apparent scattering index has frequency dependence and it is different at $200 \mathrm{kHz}$ than $38 \mathrm{kHz}$. Therefore, this index could be used to characterize the type of species. In fact, each species has its own dominant value of $A_{v}$ (Table 1).

\begin{tabular}{|l|c|c|c|}
\hline & Zostera marina & Posidonia oceanica & Laminaria hyperborea \\
\hline $\begin{array}{l}\text { Dominant value of } A_{v} \text { at } \\
38 \mathrm{kHz}\left(\mathrm{dB} \text { re } 1 \mathrm{~m}^{-1}\right)\end{array}$ & -20 & -50 & -45 \\
\hline $\begin{array}{l}\text { Dominant value of } A_{v} \text { at } \\
200 \mathrm{kHz}\left(\mathrm{dB} \text { re } 1 \mathrm{~m}^{-1}\right)\end{array}$ & -30 & -45 & -35 \\
\hline
\end{tabular}

Table 1: Dominant value of $A_{v}$ for each species at 38 and $200 \mathrm{kHz}$.

\section{DISCUSSIONS AND PERSPECTIVES}

Three species of vegetation were observed in this study. Significant differences of the acoustic response are found for each species. First, the evolution of the volume reflection between the canopy top and the bottom vary with the vegetation type. This may be due to the density or the size of leaves.

Then, a large difference in the signal attenuation is found for Posidonia oceanica and Zostera marina. A smaller attenuation is observed for Zostera marina. On the other hand, Posidonia oceanica has a smaller SAV apparent scattering index. This difference between the attenuation and reflexion evolution might be a consequence of the vegetation density. A discontinuity of the Zostera marina meadows inside the sonar footprint could explain this observation. It could be also a consequence of the presence of mat for Posidonia oceanica and not for Zostera marina.

Finally, $A_{V}$ has the potential to be used for the SAV characterisation. In fact, specific values of the SAV apparent scattering index are observed to be dependent on the species and the frequencies. It is obvious that these conclusions have to be verified with other data sets. In future work, the same species will be studied coming from other areas. Moreover, data with different densities for the same species of SAV will be surveyed. 
We will the attempt to separate $S_{V}$ and $\beta$ in order to explain the observations mentioned above. Furthermore, we will attempt to establish a connection between the SAV biomass and the coefficients $S_{v}$ and $\beta$ will be searched.
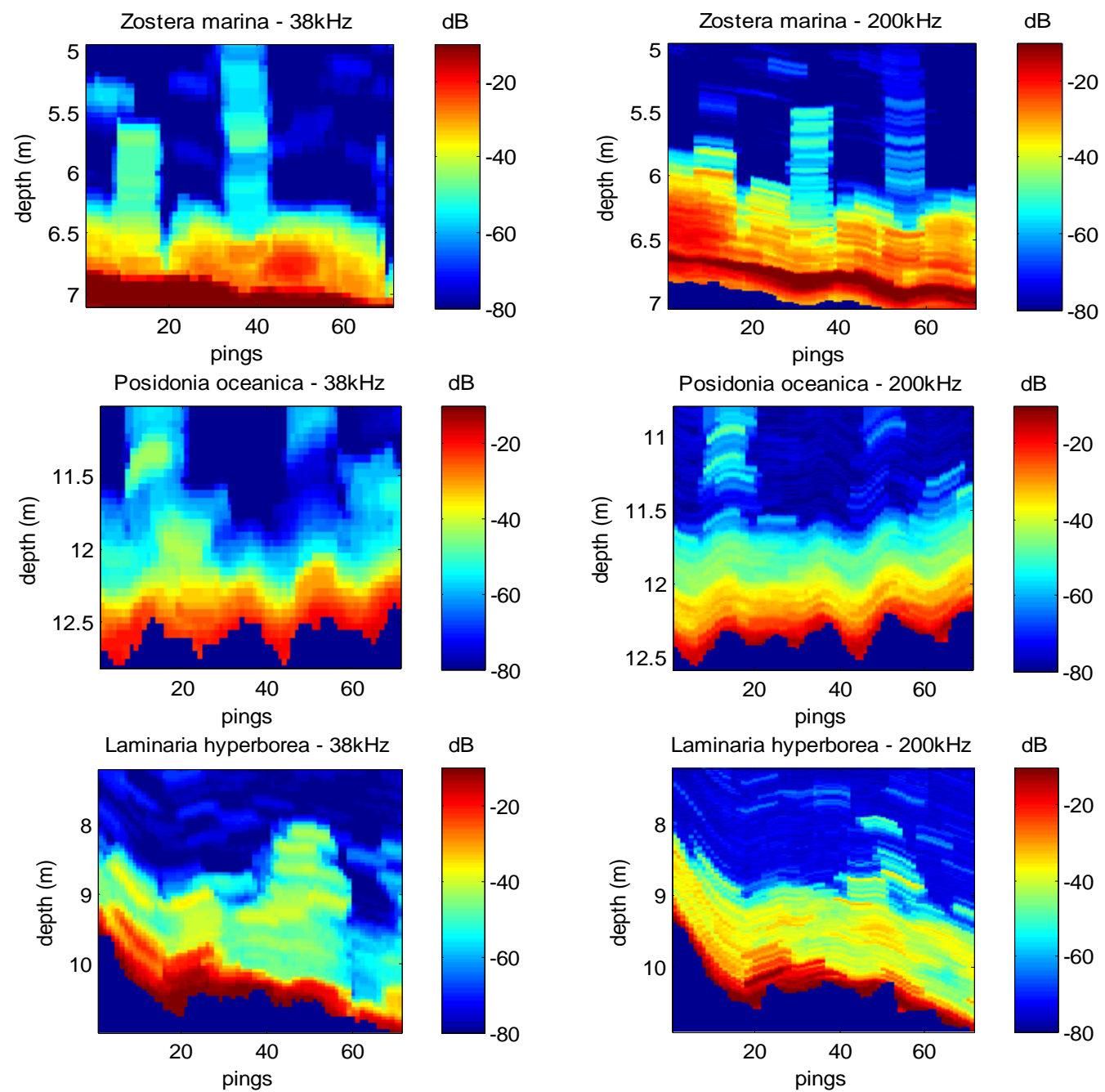

Figure 4: The SAV apparent scattering index for the studied species, at 38 and $200 \mathrm{kHz}$. The samples under the seabed are in dark blue.

\section{REFERENCES}

1. Madsen JD, Chambers PA, James WF, Koch EW, Westlake DF. 2001. The interaction between water movement, sediment dynamics and submersed macrophytes. Hydrobiologia 2001; 444:71-84.

2. Heck KL, Hays G, Orth RJ. 2003. Critical evaluation of the nursery role hypothesis for seagrass meadows. Mar Ecol Prog Ser; 253:123-136.

3. Orth RJ,Heck KL Jr, van Montfrans J. 1984. Faunal communities in seagrass beds: A review of the influence of plant structure and prey characteristics on predator-prey relationships. Estuaries; 7: 339-350. 
4. Dennison WC, Orth RJ, Moore KA, Stevenson JC, Carter V, Kollar S, Bergstrom PW, Batiuk RA. 1993. Assessing water quality with submersed aquatic vegetation. BioScience; 43: 86-94.

5. Arzel P. 1998. Les laminaires sur les côtes bretonnes. Evolution de l'exploitation et de la flottille de pêche, état actuel et perspectives. IFREMER, Plouzané, France.

6. Joubin L. 1909. Recherche sur la distribution océanographique des végétaux marins dans la région de Roscoff. Annales de l'Institut océanographique de Monaco ; 1, 1909.

7. Rollet C, Bonnot-Courtois C, and Fournier J. 2005. Cartographie des habitats benthiques en zone intertidale à partir des orthophotographies littorales. Projet REBENT, Ifremer, 13-2005-01 $: 18$.

8. Anderson JT, Holliday V, Kloser R, Reid D, and Simard Y. 2007. Acoustic seabed classification of marine physical and biological landscapes. ICES Cooperative Research Report; 286, 198 pp.

9. Forsgren G, Malmgren L, Brydsten L, and Jansson M. 1993. Characterization of sediments by high-frequency echo-sounding. Environmental Geology; 21(1):14-18.

10. Sabol M, Melton E, Chamberlain R, Doering P, and Haunert K. 2002. Evaluation of a Digital Echo Sounder System for Detection of Submersed Aquatic Vegetation. Estuaries; 25(1):133141.

11. Larkum WD, Orth RJ and Duarte CM. 2006. Seagrasses: Biology, Ecology and Conservation. Dordrecht (The Netherlands) Springer.

12. DGA/REI contract: "Cartographie de la couverture du fond marin par fusion multi-capteurs".

13. Biffard BR. 2011. Seabed Remote Sensing by Single-Beam Echosounder: Models, Methods and Applications. 2011. PhD thesis, University of Victoria.

14. Pouliquen E. 2004. Depth dependence correction for normal incidence echosounding. ECUA 2004, Delft, Netherlands.

15. Sternlicht DD and De Moustier CP. 2003. Time-dependent seafloor acoustic backscatter (10$100 \mathrm{kHz})$. The Journal of the Acoustical Society of America.

16. Lurton X and Pouliquen E. 1992. Automated sea-bed classification system for echo-sounders. IEEE Oceans Conf; 317-321.

17. Echoview Help. [online] 4 May 2012, 'http://support.echoview.com/WebHelp/Echoview.htm'. 